\title{
A LINHA DO TEMPO-MEMÓRIA COMO NARRATIVA (AUTO)BIOGRÁFICA NA UNIVERSIDADE
}

\section{THE MEMORY TIMELINE AS AN (AUTO)BIOGRAPHICAL NARRATIVE AT UNIVERSITIES}

\author{
Andrea Abreu Astigarraga \\ Universidade Estadual Vale do Acaraú (UVA) \\ Orcid.org/0000-0001-9614-1999 \\ E-mail: astigarragaandrea@yahoo.com
}

\section{INTRODUÇÃO}

A prática pedagógica é entendida, na percepção de Sacristán (1999), como Uuma ação do professor no espaço da sala de aula. Neste sentido, como podemos relacionar as memórias e experiências na construção de identidades na formação inicial docente? Pensando nisso, ao longo de vinte anos de prática docente no curso de pedagogia, tenho realizado pesquisas sobre e com os alunos/as universitários/as. Estas pesquisas começaram no ano de 2002, a partir da disciplina "História Social da Infância - componentes curriculares obrigatórios da matriz curricular".

Inicialmente, nos primeiros semestres, solicitei que os acadêmicos/as escrevessem espontaneamente sobre suas infâncias. Desde então, estas histórias de vida têm sido alvo de autorreflexão para o/a aluno/a, para a turma como um todo, para mim como pesquisadora, para monitores/as da disciplina, bem como foram instigantes para a produção dos Trabalhos de Conclusão de Curso - TCC e publicação de artigos. Depois, no mês de março de 2018, iniciamos as atividades do Grupo de Estudos e Pesquisas (Auto)biográficas - GEPAS, cujas atividades acadêmicas envolviam ensino, pesquisa e extensão.

Neste artigo, portanto, vamos descrever e analisar a Linha do Tempo de uma acadêmica, como procedimento didático-metodológico realizado nas aulas, pois "[...] a narrativa possibilita ao sujeito interpretar os fatos vivencia- 
dos, construindo uma significação pessoal para eles" (BRUNER, 1997), rompendo com a didática tradicional, vertical e supostamente neutra.

Não obstante, a principal categoria de análise da narrativa foi o conceito de "experiência formadora", desenvolvido por Josso (2004). É um método de pesquisa que busca definir a formação por meio da experiência. Para tanto, enfatiza-se o processo formativo do aprendente, partindo do ponto de vista dele e de seu processo de aprender, através das experiências vivenciadas pelo sujeito ao longo de sua trajetória de vida. Assim, possibilita-se criar e recriar sentidos e significações do aprendizado, no envolvimento e movimento de aprender a fazer, a ser e a pensar. Tudo isso, a partir da retrospectiva refletida do sujeito, constituindo-se como experiência formadora.

Para Josso (2007), o ato de narrar, "através da análise e da interpretação das histórias de vida escritas, permite colocar em evidência a pluralidade, fragilidade e a mobilidade de nossas identidades ao longo da vida" (JOSSO, 2007 , p. 415). Portanto, o principal objetivo desta pesquisa foi descrever e analisar a narrativa (auto)biográfica discente, realizada através da Linha do Tempo-Memória como prática pedagógica no ensino superior no curso de Pedagogia da Universidade Estadual Vale do Acaraú - UVA.

\section{PRÁTICAS PEDAGÓGICAS (AUTO)BIOGRÁFICAS NO ENSINO SUPERIOR}

Seguimos o entendimento de prática educativa como "[...] o conjunto das ações socialmente planejadas, organizadas e operacionalizadas em espaços intersubjetivos destinados a criar oportunidades de ensino e aprendizagem". (MARQUES; CARVALHO, 2017, p. 02). Logo, por serem práticas socialmente construídas em contextos educativos, sendo a universidade o contexto que nos interessa situar a discussão elaborada nesse texto, elas são planejadas, organizadas e operacionalizadas em dois níveis. Marques e Carvalho (2016, p. 04) definem que:

Em nível geral, são as práticas educativas previstas pelos agentes educativos (gestores e docentes) destinadas ao corpo discente. No contexto específico da sala de aula, ela é operacionalizada a partir da interação entre professores e alunos, por meio das ações que compõem a atividade de ensino e aprendizagem. Portanto, esclarecemos que não limitamos as práticas educativas à atividade de ensino e aprendizagem. Esta é, na verdade, uma dimensão dessa prática. No 
entanto, reconhecemos que a atividade de ensino e aprendizagem é o elo que torna possível a realização de determinada prática educativa.

Contudo, se tratando da formação docente, a prática educativa deve ir além da sala de aula. Em outras palavras, é preciso reinventar o espaço escolar, superando as limitações das áreas de atuação profissional, para que se possa pensar propostas inovadoras e novas metodologias, na perspectiva da prática social da educação. Assim, segundo Marques (1992, p. 153-157):

Necessita a sala de aula ser entendida como lugar de encontro para as relações educativas do face a face e, sobretudo, do ouvido a ouvido, e como tempo de trabalho de uma turma de alunos e uma equipe de professores que efetivamente a constituem: uma unidade em que se supere a fragmentação das disciplinas e das responsabilidades, em práticas orientadas por e para linhas e eixos temáticos e conceituais interdisciplinares, não apenas uma justaposição de disciplinas enclausuradas em si mesmas, mas de maneira que, em cada uma, se impliquem as demais regiões do saber.

Em concordância disso, educador e educando devem trabalhar juntos para que se formule uma aprendizagem que os assegure o trajeto condutor do conhecimento, garantindo-lhes uma evolução e aperfeiçoamento da cognição e das novas formas de mediar a prática educativa. Almeida e Pimenta (2011, p. 08) chamam a atenção para o equívoco de considerar docência "[...] uma mera vocação ou a transposição de atuações exitosas, realizadas no campo de atuação profissional". Os alunos têm que aprender de forma crítica, dando opiniões acerca dos conteúdos ministrados, sendo eles, ao lado do professor, os protagonistas de suas aprendizagens.

Nesta perspectiva, "[...] ensinar não se baseia fundamentalmente na transmissão do conhecimento, mas que supõe conseguir que o estudante desenvolva e transforme suas próprias ideias [...] é necessário um novo paradigma de docência universitária". (ALMEIDA; PIMENTA, Idem, p. 28). Portanto, os alunos não devem apenas esperar que as respostas já venham prontas do professor, é preciso que os alunos construam o conhecimento, na troca de saberes que deve acontecer na sala de aula, junto com o professor.

Desse modo, é preciso considerar que "A experiência é o que nos passa, o que nos acontece, o que nos toca. Não o que se passa, não o que acontece, ou o que toca" (LARROSA, 2002, p. 21). Pensando nisso foi que nos inspiramos na experiência com narrativas no ensino superior descrita por Bell Hooks 
(2019). Sendo assim, os professores universitários devem aprender a respeitar as suas próprias experiências, assim como têm necessidade de falar sobre elas em sala de aula. Nesse sentido, pensar acerca de uma formação decorrente de nossas experiências é valorizar nossa prática docente; é significá-las, logo, refleti-las, aspecto crucial na constituição docente.

Portanto, não se pode negar que essas experiências são importantes para o processo de aprendizado, considerando também que: "[...] cada aluno tem suas lembranças, sua família, sua religião, seus sentimentos, sua língua, sua cultura, uma voz característica. Podemos encarar essa experiência criticamente e ir além dela. Mas não podemos negá-la" (GIROUX apud BELL HOOKS, 2019, p.120). Então, a experiência narrada pelos/as professores/as e as experiências dos/as acadêmicos/as devem existir em sala de aula de forma dialético-dialógica.

Para Hooks (2019), uma prática simples, como a de incluir a experiência pessoal, pode ser mais construtiva e desafiadora que o simples ato de mudar o currículo. É por isso que se criticou tanto o lugar da experiência - da narrativa confessional - na sala de aula. Consequentemente, uma das ações por que alguns colegas professores céticos sobre a pedagogia progressista acreditam ser descredibilizados, quanto professores universitários, é deixar que alunos, ou o próprio educador, falem sobre suas experiências.

Sem embargo, o ato de partilhar narrativas pessoais, ligando esse conhecimento à informação acadêmica, realmente aumenta nossa capacidade de conhecer. Quando um professor fala por meio do ponto de vista das suas experiências imediatas, um elo de confiança é estabelecido entre o profissional e os alunos, às vezes, pela primeira vez. Isso porque o enfoque da experiência permite aos alunos tomarem posse de uma base de conhecimento a partir da qual podem falar.

Bell Hooks (2019, p. 200) descreve na sua prática pedagógica, através de narrativas (auto)biográficas, que precisou modificar a tradição em que "[...] a voz do professor era a única que deveria ser ouvida". E um dos grandes desafios foi "[...] intervir para alterar a estrutura pedagógica existente e ensinar os alunos a escutar, a ouvir uns aos outros" (BELL HOOKS, 2009, p. 200). Fazendo isso, percebemos o quanto temos em comum nas nossas experiências, que são particulares e singulares, ao mesmo tempo.

Posto isso, 
A partilha de experiências e narrativas confessionais em sala de aula ajuda a estabelecer o compromisso comunitário com o aprendizado. Esses momentos narrativos são, em geral, o espaço onde se rompe o pressuposto de que todos nós partilhamos as mesmas origens de classe e os mesmos pontos de vista (BELL HOOKS, 2019, p. 247).

Assim, é necessário enfatizar as diferenças e singularidades, que nos ajudam a perceber e entender o outro e suas características. É relevante também entender a explicação da autora supracitada sobre a VOZ como narrativa (auto)biográfica em sala de aula:

Um dos aspectos menos compreendido dos meus escritos sobre pedagogia é a ênfase na voz. Achar a própria voz não é somente o ato de contar as próprias experiências. É usar estrategicamente esse ato de contar - achar a própria voz para também poder falar livremente sobre outros assuntos. É disso que muitos professores universitários têm medo [...] os alunos de instituições públicas, a maioria deles de origem trabalhadora, chegam à faculdade supondo que os professores entendem que eles não têm nada de bom a dizer, nenhuma contribuição valiosa a apresentar para uma troca dialética de ideias (BELL HOOKS, 2019, p. 199).

Ademais, é fundamental saber que os cursos de ciências Humanas, especialmente a Pedagogia, envolvem discentes da classe trabalhadora, que trazem consigo, ao ingressar no ensino superior, experiências de pobreza, abandono, trabalho infantil, abusos físicos etc. Essas histórias precisam, pois, ser consideradas como experiências formadoras, para além dos conteúdos acadêmicos.

\section{A LINHA DO TEMPO COMO EXPERIÊNCIA FORMADORA E PRÁTICA PEDAGÓGICA NO ENSINO SUPERIOR}

Todos nós, seres humanos, acumulamos, no decorrer de nossas vidas, experiências que constituem nossas identidades. Todavia, essa constituição de ser humano não se configura como uma estrutura fixa e imutável, visto que

Podemos ser transformados por tais experiências, de um dia para o outro ou no transcurso do tempo, pode ler-se outro componente fundamental da experiência: sua capacidade de formação ou de transformação. Somente o sujeito da experiência está, portanto, aberto à sua própria transformação (LARROSA, 2002, p. 26). 
Por isso, é importante registrar nossas vivências. É a partir desta lógica que se faz compreender que o procedimento didático-pedagógico utilizado na disciplina de "História Social da Infância" é a Linha do Tempo, um dispositivo de escuta narrativa. Para isso, através da ludicidade do desenho em sala de aula, cada universitário/a expressa os acontecimentos que considera mais significativos em sua história de vida, do seu nascimento ao dia em que realiza essa atividade. A recordação-memória de fatos marcantes e o registro (auto) biográfico são alcançados com o suporte da literatura e da atividade lúdica, que funcionam como mediadores para que os conteúdos narrativos possam emergir. Assim, a pesquisa (auto)biográfica instiga a pessoa a narrar e a revelar suas vivências.

Portanto, a Linha do Tempo é um procedimento didático-pedagógico de pesquisa, de abordagem qualitativa, com viés participativo. Não obstante, apresentar a sua Linha do Tempo aos colegas é uma atitude de vontade própria, de desejo pessoal de compartilhar suas experiências, pois: "Fazer a vida nunca foi fácil. Ganhá-la, também não. Compreendê-la, menos ainda" (PINEAU; LE GRAND, 2012, p. 15). Por esse motivo, este dispositivo formativo contribui para a reflexão (auto)biográfica de discentes na formação inicial de docência.

O procedimento é realizado nas seguintes etapas: Inicialmente, solicito que cada aluno leve para a aula do dia seguinte: papel madeira ou cartolina, giz de cera, canetinha e lápis de cor. No dia proposto, sugiro que os estudantes escolham algum espaço dentro ou fora da sala de aula e se sentem confortavelmente para desenvolver um desenho. Então, eu explico como cada um/a pode construir sua linha do tempo, de forma subjetiva e também dou sugestões. Todavia, recomendo que primeiro façam um rascunho em uma folha de papel para posteriormente registrar na cartolina ou papel madeira. No final da atividade, solicito aos/às discentes que se sintam confortáveis para compartilhar para a turma sua produção final, por meio de um relato oral.

Não raro, há momentos de fortes emoções, devido aos conteúdos presentes nas narrativas: pobreza, fome e seca; migração dos parentes para outros estados em busca de melhores condições de vida; ausência dos parentes/ pais; doação de filhos para outras pessoas e/ou parentes, por falta condições financeiras. Contudo, também há lembranças do início da escolarização; os/ as professores/as mais queridos/as; os primeiros amores/ beijos; viagens com 
a família para outras cidades/ estados; alegria da aprovação no vestibular; dentre outras.

Isto posto, concordamos com Lima (2004) quando afirma que nos construímos professoras a partir da nossa memória: da nossa experiência como estudantes e das relações significativas que tivemos nesse percurso; da nossa formação técnico-acadêmica, na qual sustentamos nossas visões baseadas nas teorias; da nossa formação humana, que tem origem na nossa história pessoal, nos valores familiares, morais e sociais que desenvolvemos; e por meio das experiências que a própria docência nos propicia.

\section{MEMÓRIA}

Certamente, cada pessoa organiza suas reminiscências de forma particular e específica, o que configura, obviamente, a idiossincrasia que singulariza cada indivíduo. Desta forma, ao tentar transferir essas memórias por meio de recursos visuais, os alunos ativam a criatividade e tentam, além de expressar suas vivências.

No que se pese a isso, quando vamos analisar memórias de infância, é importante evidenciar que se trata de rememorações seletivas, que vêm à tona à medida que estão sendo contadas - memórias de adultos no presente relatando um tempo passado a partir das experiências e da seleção individual de cada universitária/o. Tal aspecto é apresentado, pois queremos guardar o devido distanciamento do pesquisador atento à relação entre o "aproximar-se e o distanciar-se" (ELIAS, 1997 apud SARAT; CAMPOS, 2017, p. 1259) do objeto analisado, principalmente porque o material empírico impõe essa relação, o que permite conferir rigor acadêmico. Outrossim, falamos das fontes que são as memórias de infâncias, imersas em emoções e subjetividades, à mercê do controle individual (SARAT; CAMPOS, 2017).

Dessa maneira, o compartilhamento das narrativas (auto)biográficas propicia um ambiente de escuta, de compreensão e compartilhamento de emoções diversas, o que nos leva a crer que

O trabalho biográfico não consiste somente em fazer reemergir essas lembranças pertinentes à vista do questionamento que orienta esse trabalho. Uma vez que a perspectiva biográfica com a qual eu trabalho abraça a história de uma 
vida, é preciso chegar a um momento charneira de reconstrução de quem faz história no percurso de vida relatado. É o momento em que se trata de compreender como essa história articula-se como um processo - o processo de formação - que pode ser depreendido mediante as lições das lembranças que articulam o presente ao passado e ao futuro. Será o estabelecimento dessa perspectiva temporal que permitirá nomear os 'argumentos' da história. Nessa fase do trabalho biográfico centrado na compreensão e na interpretação dos relatos com olhares cruzados, novos tipos de laços aparecerão (JOSSO, 2006, p. 6).

Além disso, Ricoeur (2007) identifica na fenomenologia de Santo Agostinho sobre a memória a tradição do olhar interior: "Ao se lembrar de algo, alguém lembra de si" (RICOEUR, 2007, p. 107). Essa frase remete ao caráter privado da memória, radicalmente singular: "minhas lembranças não são as suas" (RICOEUR, 2007, p. 107). Logo, as lembranças não são transmissíveis de uma pessoa para outra, assim como as do meu passado outorgam uma posse.

Por outro lado, Ricoeur (2007) também identifica, em Halbwachs, a tradição do olhar exterior sobre a memória. Esse autor analisa os "quadros sociais da memória", considerando que as reminiscências não ficam adstritas ao mundo da pessoa (relações entre o corpo e o espírito, por exemplo), mas perseguem a realidade interpessoal das instituições sociais. consequentemente, por sua vez, "Os fatos sociais consistem em modos de agir, pensar e sentir, exteriores ao indivíduo e dotados de um poder coercitivo pelo qual se lhe impõem" (HALBWACHS apud BOSI, 1995, p. 55).

Então, é possível afirmar que mudança de visão está na própria formulação do objeto a ser apreendido. A memória do indivíduo, portanto, depende do seu relacionamento com a família, com a classe social, com a escola, com a igreja, com a profissão. Enfim, com os grupos de convívio e com os grupos de referência peculiares a esse indivíduo.

Lembramos, então, porque os outros e a situação presente nos fazem lembrar: "O maior número de nossas lembranças nos vem quando nossos pais, nossos amigos ou outras pessoas nos provocam" (BOSI, 1995, p. 62). Assim, Halbwachs (apud BOSI, 1995) amarra a memória da pessoa à memória do grupo e esta última à esfera maior da tradição, que é a memória coletiva de cada sociedade. O que o autor também realça é a iniciativa que a vida atual do sujeito toma ao desencadear o curso da memória: 
Lembrar não é reviver, mas refazer, reconstruir, repensar, com imagens e ideias de hoje, as experiências do passado. A lembrança é uma imagem construída pelos materiais que estão, agora, à nossa disposição, no conjunto de representações que povoam nossa consciência atual. (HALBWACHS apud BOSI, 1995, p. 60)

Destarte, por mais nítida que nos pareça a lembrança de um fato antigo, ela não é a mesma imagem que experimentamos na infância, "[...] porque nós não somos os mesmos de então e porque nossa percepção alterou-se e, com ela, nossas ideias, nossos juízos de realidade e de valor" (BOSI, 1995, p. 56). A verdadeira potência do vivido se encontra na possibilidade de interpretá-lo de formas diferentes, buscar significações que melhorem, por exemplo, as vivências de infância hoje.

Consoante a isso, Ricoeur (2007) critica e sintetiza as duas perspectivas antagônicas de olhar interior e exterior da memória. Para ele,

[...] nem a sociologia da memória coletiva nem a fenomenologia da memória individual conseguem derivar, da posição forte que ocupam respectivamente a legitimidade aparente da tese adversa: coesão dos estados de consciência do eu individual, de um lado; capacidade das entidades coletivas de conservar e recordar as lembranças comuns, do outro (RICOEUR, 2007, p. 134).

Diante das duas perspectivas antagônicas, Ricoeur (2007) propõem um terceiro pressuposto: "assimetria entre a atribuição a si e a atribuição ao outro, no próprio cerne da atribuição múltipla" (RICOEUR, 2007, p. 137). Ele propõe a categoria de "relação com os próximos", segundo a qual

[Não] existe, entre os dois pólos da memória individual e da memória coletiva, um plano intermediário de referências no qual se operam concretamente as trocas entre a memória viva das pessoas individuais e a memória pública das comunidades às quais pertencemos? [...] os próximos, essas pessoas que contam para nós e para as quais contamos, estão situadas numa faixa de variações das distâncias na relação entre si e os outros". (RICOEUR, 2007, p. 141)

Os próximos estarão presentes na narrativa da acadêmica pesquisada em forma de parentes, amigos e professores, mostrando a relação entre memória individual e coletiva. 


\section{INFÂNCIA}

Admitimos, consoante a Larrosa (2004), que a infância desestabiliza “[...] a segurança de nossos saberes, questiona o poder de nossas práticas e abre um vazio em que se abisma o edifício bem construído de nossas instituições de acoIhimento" (LARROSA, 2004, p. 184). Isso ocorre porque os conceitos de criança e infância são corriqueiramente idealizados como sendo únicos, descontextualizados, homogêneos e universais. Para Demartini (2002), “[...] há diferentes maneiras como a infância pode ser sentida e relatada e diferentes representações" (DEMARTINI, 2002, p. 09). É neste sentido que a metodologia adotada nesta pesquisa busca possibilitar que a criança vivida e lembrada no adulto tenha esse local de fala - e não apenas de escuta no processo educacional.

Portanto, ideias limitantes sobre o conceito de infância criam uma marginalização identitária de sujeitos que não se enquadram no modelo ideal/ perfeccionista de infância. Exatamente por esse motivo, este é um debate importante a ser realizado no âmbito universitário, sobretudo nos cursos de Pedagogia, pois é preciso ter um olhar mais sensível sobre a realidade social na qual estamos inseridos. Sobre o assunto, Santos (2016) nos diz que a maneira como os indivíduos e, em particular, os professores compreendem a infância e a criança pode influenciar nas suas abordagens profissionais e no modo como lidam com esse fenômeno.

Como seres sociais, nossas experiências singulares são contextualizadas no tempo e no espaço onde estamos inseridos. Sendo assim, nossas infâncias, muito provavelmente, vão diferir. Mas, o mosaico delas pode mostrar parte de nosso painel social, visto em ângulos diferentes. Então, possibilitar um debate acerca da construção das infâncias é também entender como elas estão sendo construídas no seio de nossa sociedade. Da mesma forma, estimular a memória da infância vivida em sala de aula modifica a prática educativa. Foi uma grande experiência, uma grande reflexão poder me perceber na sociedade, relembrar cada uma das coisas de minha vida, quando fui criança. Isso reflete, consequentemente, na acadêmica quem eu me tornei mais tarde.

Portanto, de acordo com Marques,

Em vez de o professor operar com conceitos que já aprendeu e na forma em que os aprendeu e que agora só necessitariam ser reproduzidos por nós e pelos alunos, trata-se, no ensino, de ele e os alunos produzirem, em entendimento co- 
mum, os conceitos com que irão operar para entenderem as relações com que lidam. Não se trata de chegar a soluções dadas às questões/aos problemas, mas de inventar, em cada situação e em cada comunidade de sujeitos, os conceitos com que irão operar sobre os temas que analisam (1992, p. 561).

Destarte, possibilita-se que o aluno tenha autonomia no seu processo educacional, rompendo com a tendência passiva que tem sido cobrada dos alunos durante tantas décadas.

\section{CONSTRUÇÃOO DA IDENTIDADE (AUTO)BIOGRÁFICA}

A formação da identidade profissional integra todas as identificações feitas sobre determinada profissão ao longo da vida. Dito de outra forma, "A formação da identidade ocupacional pertence a cada indivíduo inserido em sua história, e deverá continuar pertencendo, enquanto projeto de vida ou de futuro." (LEVENFUS, 1997, p. 122). Garcia, Hypolito e Vieira (2005) ainda acrescentam sobre as relações laborais que

As posições de sujeito que são atribuídas, por diferentes discursos e agentes sociais, aos professores e às professoras no exercício de suas funções em contextos laborais concretos. Refere-se ainda ao conjunto das representações colocadas em circulação pelos discursos relativos aos modos de ser e agir dos professores e professoras no exercício de suas funções em instituições educacionais, mais ou menos complexas e burocráticas. (GARCIA; HYPOLITO; VIEIRA, 2005, p. 48).

Para Pimenta (1996), a identidade docente se constrói pelo significado que cada professor dá para a sua profissão, enquanto autor e ator, conferindo à atividade docente a idiossincrasia necessária a este processo. Então, isso reflete no cotidiano do professor, a partir de seus valores, de seu modo de situar-se no mundo, de sua história de vida, de suas representações, de seus saberes, de suas angústias e de seus anseios.

Não obstante, um dos fatores que têm fortalecido esta prática docente é a escuta sensível às histórias de vida e às narrativas (auto)biográficas como uma prática pedagógica, uma vez que "A história de vida, aqui definida como busca e construção de sentido a partir de fatos temporais pessoais, envolve um processo de expressão da experiência" (PINEAU; LE GRAND, 2012, p. 15). Assim, de acordo com Pineau e Le Grand (2012), o território das escritas 
do eu envolvem os meios escritos, integrando à fala a dimensão da comunicação oral da vida.

No que diz respeito ao ambiente educacional, diferentemente de algumas outras profissões. Neste viés, a narrativa (auto)biográfica de universitários sobre suas infâncias nos proporciona - na relação ensino, pesquisa e extensão - abertura curricular para práticas didático-pedagógicas em que a experiência e a vivência possibilitem uma perspectiva mais ampla sobre educação, já que, para Santos (2008), "Todo conhecimento é autoconhecimento". (SANTOS, 2008, p.80).

Por esse motivo, a reflexão (auto)biográfica se situa como emergente, não só no âmbito da Sociologia, mas também, no âmbito da Pedagogia. Consequentemente, uma abordagem como essa implica também cientificidade, já que

Nossas trajetórias de vida, nossos valores e nossas crenças são a prova íntima do nosso conhecimento, o que permite afirmar que os sentidos atribuídos ao conhecimento vinculam-se à nossa história. Assim, o caráter (auto)biográfico da ciência, já apontado como vínculo ao fato de que a explicação científica dos fenômenos à auto-justificação da ciência enquanto fenômeno central da nossa contemporaneidade (SANTOS, 2008, p. 52)

A pesquisa (auto)biográfica pode ser caracterizada, pois, como um procedimento de entender e trazer à tona as explicações do que nos transformamos; e isso se faz mediante a investigação dos dados da própria vivência proporcionando uma visão da constituição da vida desde a infância até a vida adulta. Impulsionando-nos a termos um aspecto global de nossa formação de vida, nossa formação humana. Dessa forma, a abordagem (auto)biográfica é imprescindível no que diz respeito à investigação dos dados da vivência de alguém, já que ela denota num autoconhecimento de si mesmo.

Portanto, é de fundamental importância compreender que os estudos que incidem sobre a pesquisa (auto)biográfica possibilitam demonstrar como os sujeitos estabelecem relações consigo, com o outro e com o mundo; ou seja, com o vivido no tempo em que fazem parte e ao qual pertencem.

Em Educação, a pesquisa (auto)biográfica "[...] amplia e produz conhecimento sobre a pessoa em formação, as suas relações com territórios e tempos de aprendizagem e seus modos de ser, de fazer e de biografar resistências e 
pertencimentos" (DELORY-MOMBERGUER, 2008, p. 23). Então, enfatizamos que esse tipo de pesquisa instiga a pessoa a narrar e a revelar suas vivências ao longo da vida. Dessa maneira, os/as universitários/as conseguem biografar sobre si mesmos e sobre o mundo do qual fazem parte, produzindo, intercalando e envolvendo para si e para as pessoas suas experiências de vidas.

Isto nos faz refletir sobre a relevância da dimensão subjetiva na constituição curricular para que a universidade escute e conheça seus discentes, possibilitando um elo entre a identidade experiencial-subjetiva e de formação humana e acadêmica-profissional dos universitários.

A partir de uma visão culturalista, que enfatiza a função das narrativas no pensamento e na ação humana, Bruner (1997) destaca que, após a longa tradição essencialista na Psicologia, passou-se a conceber o self como um contador de histórias. Em mesma proporção, a virada narrativa estimulou uma nova perspectiva sobre a pessoalidade, passando-se a considerar o "eu" como um narrador estratégico, cujas histórias se entrelaçam às histórias alheias e variadas, em diálogos e em conflitos. Assim, "Podemos indagar porque uma história é contada e não outra. Esse questionamento conduziu à suspeita de que concepções oficiais ou forçadas do si-mesmo poderiam ser usadas para estabelecer controle político ou hegemônico de um grupo sobre outro" (BRUNER, 1997, p. 99).

\section{PROCEDIMENTO METODOLÓGICO}

Para a pôr em prática o método Linha do Tempo-Memória, foi necessário que a universitária participante lesse e assinasse o termo de Consentimento e Livre Esclarecido - TCLE. Tivemos o cuidado de garantir o anonimato e preservar a identidade dela. O critério de escolha desta Linha do Tempo foi possível devido à disponibilidade da universitária em contar e publicar a sua narrativa, considerando que seria uma possibilidade de contribuir de forma didática para a divulgação de uma proposta metodológica ativa e inovadora nas práticas pedagógicas. Nesta atividade, consideramos a dimensão subjetiva da participante, estimulando-a a relatar o que ela considerar significativo. Assim, a universitária (A) construiu sua Linha do Tempo por meio do desenho de um trem com vários vagões. Como se vê na ilustração a seguir. 


\section{Construção da Linha do Tempo-Memória em sala de aula: os vagões do trem-metáfora no percurso da memória da infância \\ Título: Construção da Linha do Tempo em sala de aula}

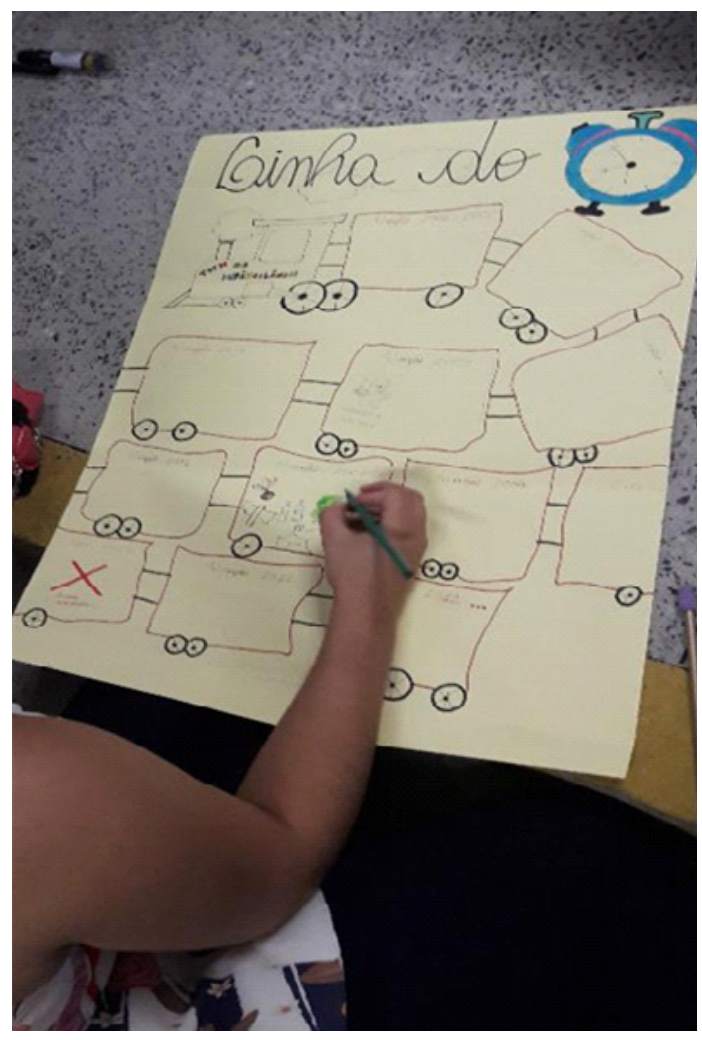

Fonte: Acervo pessoal da pesquisadora

Refletir sobre nossas experiências na infância em um componente curricular do curso de pedagogia, nos parece imprescindível à formação pessoal e profissional de acadêmicos/as na formação inicial. Percebe-se o impacto que isso causa antes, durante e depois do desenvolvimento da disciplina História Social da Infância. Situações vividas na infância, tornam-se experiências pessoais e coletivas refletidas à luz de estudiosos do tema.

Foi uma grande experiência, uma grande reflexão poder me perceber na sociedade, ver que cada uma das coisas da minha vida, quando fui criança, reflete 
diretamente em quem eu me tornei mais tarde. Ao ter a oportunidade de realizar a atividade, organizá-la da melhor maneira para mim e poder desenhar, representando na folha de papel madeira a minha trajetória da infância, utilizei traços que formaram um trem e em cada vagão encontram-se minhas memórias mais pessoais e muitas que estavam guardadas e nunca tinham tido importância para ninguém, além de mim mesma. Foi de suma importância realizar a atividade Linha do Tempo, para poder construir um olhar sobre a criança de uma maneira mais crítica, desenvolver um conhecimento sobre infâncias e perceber a relação da criança com a sociedade. Com toda certeza fez uma grande diferença no meu saber e consequentemente fará uma grande diferença no meu agir pessoal e profissional. A criança em sociedade tem que se percebida e valorizada. A importância de perceber a criança em sociedade é essencial. E se não cuidarmos de suas vidas? E se não dermos importância a sua história? E se não respeitarmos seu tempo e sua capacidade? São perguntas que devemos fazer para chegarmos a uma proposta pedagógica e ver o quão as crianças são importantes em sociedade (acadêmica).

Sobre a escolha deste formado da Linha do Tempo, a acadêmica justifica-se, apresentando uma analogia entre algumas fases da vida e os vagões do trem. Nas palavras dela:

Minhas considerações em relação a realização da atividade Linha do Tempo proposta pela professora foi muito prazeroso e ao mesmo tempo bastante desafiador, pois relatar fatos de nossa vida é algo que exige sensibilidade na escrita, abertura pessoal e também uma postura de orador. Ao receber a proposta de realizar uma linha do tempo contando partes da minha história, veio na cabeça o desenho de um relógio, que representa leitura do tempo e mede a história de cada indivíduo. Mas, também me veio na cabeça a imagem de um trem. Por que um trem? Cada vagão poderia representar uma parte da minha história, cronometrada, vivida, e parte de um todo e assim fiz um trem com 11 vagões, destacando, em cada um, fatos importantes da minha infância que marcaram a minha história por completo. O ser humano é composto por vivências e experiências únicas da qual devemos respeitar.

Verificamos que a acadêmica inicia sua narrativa (auto)biográfica fazendo considerações-avaliações sobre a atividade didática-metodológica da Linha do Tempo, qualificando-a como prazerosa e, ao mesmo tempo, desafiador. Segundo ela, trata-se de "[...] algo que exige sensibilidade na escrita, abertura pessoal e também uma postura de orador". Essa sensibilidade de que a discente trata diz respeito à escrita de um texto original sobre si mesma, uma disponibilidade de abrir-se para si e para o outro. Ao mesmo tempo, refere-se 
também à postura de orador, de escritor e de editor de sua narrativa (auto) biográfica. Assim como apresenta a possibilidade de criação artística subjetiva, o que a possibilitou escolher construir a sua Linha do Tempo-Memória em forma de um desenho de um trem, como metáfora de experiência formadora.

Neste sentido,

O que representa um desafio neste conhecimento de si mesmo não é apenas compreender como nos formamos por meio de um conjunto de experiências, ao longo da nossa vida, mas sim tomar consciência de que este reconhecimento de si mesmo como sujeito, mais ou menos ativo ou passivo segundo as circunstâncias, permite à pessoa, daí em diante, encarar o seu itinerário de vida, os seus investimentos e os seus objetivos na base de uma auto-orientação possível, que articule de uma forma mais consciente as suas heranças, as suas experiências formadoras, os seus grupos de convívio, as suas valorizações, os seus desejos e o seu imaginário nas oportunidades socioculturais que soube aproveitar, criar e explorar, para que surja um ser que aprenda a identificar e a combinar constrangimentos e margens de liberdade (JOSSO, 2012, p. 12).

De forma detalhada, a seguir, a acadêmica especifica o que cada um dos vagões representava:

No primeiro vagão, anos 2001 e 2002, meu nascimento e comemoração do $1^{\circ}$ ano de vida, que é algo muito singular de cada indivíduo.

No segundo vagão, foi marcado pelo início da vida escolar, em 2003, a entrada na creche.

No terceiro vagão destaquei a minha ida para São Paulo com meus pais, que foi algo muito importante por conta das mudanças de vivências.

No quarto vagão, destaquei um presente que marcou a minha infância, uma elefoa de pelúcia que ganhei dos meus pais, da qual coloquei o nome de Dolores por conta do meu filme preferido, quando criança.

No quinto vagão, destaquei a festinha do $A B C$ por ser uma data memorável para mim, pois foi um ritual de passagem para o ensino fundamental, do qual eu passei de ano e celebrei.

No sexto e sétimo vagão, destaquei a fase da minha infância cheia de brincadeiras e diversão, onde a única preocupação era ir à escola e estudar. (a acadêmica)

Observe-se que entre o primeiro e o sétimo vagão do trem-metáfora, a acadêmica descreve uma cronologia que vai do nascimento dela ao início 
da vida escolar. De forma semelhante, destaca as vivências lúdicas, como as brincadeiras e o brinquedo preferido. Assim como menciona uma experiência diferenciada de viagem a outro estado - São Paulo -, com sua família, antes do falecimento do seu pai.

Ela prossegue fazendo analogias, acrescentando que

No oitavo e nono vagão destaquei momentos de confusão emocional, traumas e experiências dolorosas em relação a minha vida, por conta dos anos 2009 e 2010 ter sido de bastante sofrimento para mim, por conta do falecimento do meu pai e por membros da minha família terem adoecido seriamente. Foi uma fase da qual eu estava entrando na adolescência e como mulher, essa não foi uma fase nada fácil de superar, mas a superação chegou e a recuperação emocional também. (a acadêmica)

O oitavo e o nono vagão do trem-metáfora apresentam a passagem da infância para a adolescência, com a descoberta da sexualidade e o desafio de cuidar dos familiares doentes após a morte de seu pai. Esses fatos, todavia, provocaram um amadurecimento precoce, contado em sala de aula com mais detalhes do que a narrativa escrita acima. Logo, é importante dar destaque para essa parte do relato, contendo elementos de superação desta fase difícil para uma criança que estava começando a vida adolescente.

Por fim, a acadêmica, finaliza sua exposição com uma conclusão dos fatos apresentados: "No décimo e décimo primeiro vagão finalizei com a valorização da escola, destacando o qual importante a escola e alguns professores e gestores foram importantes para o meu desenvolvimento pessoal e acadêmico" (a acadêmica). Perceba-se, pois, como nos dois últimos vagões do trem-metáfora, a acadêmica destaca a valorização da escola e o papel dos professores e gestores em seu percurso formativo.

$\mathrm{Na}$ análise de sua narrativa (auto)biográfica, a acadêmica relaciona a atividade didática-metodológica realizada me sala de aula com a sua formação acadêmica e profissional, demonstrando a forte relação entre história de vida e formação profissional. Segundo Nóvoa (2013), o processo identitário da profissão perpassa a dimensão do eu pessoal e do eu profissional.

Ao fim da construção da atividade da Linha do Tempo comecei a fazer uma breve análise sobre como foi toda minha vida e tudo o que me fez ser quem sou e também a escolher a Pedagogia como profissão. A primeira resposta foram os exemplos de profissionais que tive e a segunda resposta é a força de vontade 
de valorizar vidas e poder contribuir de uma maneira direta na sociedade, ou seja, formar pessoas. A docência é uma profissão bastante humana. Pessoas que atuam na área educacional precisam ter uma escuta sensível e estar atenta às narrativas de cada um de seus alunos e alunas. É a partir da escuta sensível e de observações minuciosa dos relatos orais que o professor ou a professora poderá construir maneiras humanas de instigar o conhecimento. (acadêmica)

E, finalmente, a acadêmica participante da pesquisa relata que um dispositivo didático-investigativo aparentemente simples contem em si potencial reflexivo e transformador.

Todas as minhas reflexões foram tiradas de uma atividade aparentemente simples e muito fácil de fazer: a Linha do Tempo. Quando nos percebemos, nos encontramos e nos valorizamos como seres humanos, os passos seguintes são: querer mudar o que não é adequado; adaptar o que é necessário; e criar formas de expressão. E quanto mais cedo isso acontecer, mais rápido os resultados apareceram. Pois, na realização da atividade Linha do Tempo teve uma ação transformadora na minha vida, pois em sua realização me percebi enquanto aluna e pessoa, uma parte da sociedade acadêmica e do lugar em que vivo também (acadêmica)

Percebe-se na narrativa da acadêmica os sentidos e o significado que a atividade refletiu em sua formação, o olhar para si e o reconhecimento dos "territórios que habitam" e são por ela "habitados" (PASSEGGI; SOUZA; VICENTINI, 2011, p. 371) na perspectiva da reflexividade e de sua autoformação.

\section{CONSIDERAÇÕES FINAIS}

O principal objetivo desta pesquisa foi descrever e analisar a relação entre narrativas (auto)biográficas realizadas através da Linha do Tempo-Memória como experiência formadora e prática pedagógica no ensino superior, o que possibilita, consequentemente, a narrativa (auto)biográfica discente.

Verificamos nesta narrativa (auto)biográfica, realizada pela universitária, na sua Linha do Tempo-Memória, vários aspectos a serem destacados: a importância de ser usada uma metodologia didático-pedagógica e lúdica que possibilite um espaço de narratividade vivencial em sala de aula; a relação entre o saber acadêmico (leituras de textos sobre o tema infância) e a vivência da infância real; a ampliação do conceito de criança e infâncias, bem 
como a formação de um novo olhar sobre elas na sociedade; identificação e definição profissional com a Pedagogia; a construção de uma narrativa de vida subjetiva através do desenho-metáfora dos vagões de trem; expressão de memórias individuais íntimas confiadas ao grupo; a valorização da Linha do Tempo enquanto atividade didático-pedagógica "aparentemente simples e fácil de fazer, mas que possibilitou transformação pessoal e acadêmica", como ela mesma afirmou.

Além de tudo isso, ouvir as narrativas (auto)biográficas dos/as acadêmicos/as do Curso de Pedagogia tem proporcionado transformações pessoais e coletivas nos âmbitos interno e externo do curso. Encontramos, na análise dos dados, indícios de processos de significação, tais como: consciência da divisão de classe social; discriminação étnico-racial e de gênero; mudanças de comportamento no âmbito privado; envolvimento e engajamento em pesquisas e atividades de extensão. É necessário considerar, todavia, o paradigma emergente onde brotem valores da diversidade, assim como a perspectiva subjetiva (auto)biográfica e política de criar espaços de escuta. Isso faculta ouvir os sujeitos das diversas camadas sociais, identidades étnicas e de gênero para que suas histórias de vida sejam manifestadas livremente no espaço acadêmico, integradas e incorporadas aos saberes pedagógicos e curriculares para, assim, construir práticas docentes libertadoras e inclusivas.

Portanto, essa perspectiva didático-metodológica investigativa traz consigo uma abordagem subjetiva e política, o que nos faz ver a necessidade da transformação social tão desejada pela Pedagogia progressista libertadora, através da consciência crítica. Esta prática educativa, que evoca a memória da infância vivida de forma dialógica e intersubjetiva, desvia-se da racionalidade instrumental positivista e sobrepuja o mundo subjetivo dos universitários. Assim, essa perspectiva da experiência formadora nos ajuda a abandonar as idealizações que nos privam da criticidade sobre a realidade, de modo que passamos a perceber que a segregação social, que engloba grande parcela da população, inclui também alguns acadêmicos. Logo, somos levados a organizar experiências realmente provocadoras de aprendizagem na formação de professores.

Para finalizar, é importante que seja enfatizado que a pedagogia progressista libertadora nos fala que o indivíduo e sua "bagagem de vida" podem e devem ser levados em consideração pelo/a educador/a, por mais simples ou irrelevante que estas experiências possam parecer. Deve-se res- 
peitar, portanto, a dignidade humana e autonomia do educando. Se quisermos uma transformação profunda na sociedade, esta deverá começar pelo e no indivíduo. Um bom começo seria lançar luz à forma com que este/a futuro/a educador/a se percebe no microcosmo que é a sala de aula. Logo, mudanças que não respeitem a cultura e a subjetividade dos acadêmicos/ as serão sempre "mais do mesmo". Dito de outra forma, a mudança é individual e, ao mesmo tempo, dialético-dialógica, pois, como formadores/ as de educadores/as, devemos sempre incentivar essa busca autocrítica e o confronto produtivo de ideias.

\begin{abstract}
Resumo: Esta pesquisa parte do seguinte questionamento: a experiência formadora e a (auto)biografia têm sido validadas como práticas pedagógicas na universidade? Neste viés, o principal objetivo foi descrever e analisar a narrativa (auto)biográfica discente, realizada através da Linha do Tempo-Memória como prática pedagógica no ensino superior no curso de Pedagogia da Universidade Estadual Vale do Acaraú - UVA. Para isso, é preciso compreender que a Linha do Tempo, atividade lúdico-subjetiva, pode ser caracterizada como um dispositivo de narrativa de escuta (auto)biográfica discente e como prática pedagógica docente na universidade, dentro de um movimento dialético-dialógico. Esta prática educativa, que evoca a memória da infância vivida de forma dialógica e intersubjetiva, desvia-se da racionalidade instrumental positivista. Isto provoca, pois, uma reflexão sobre a relevância da dimensão subjetiva na formação da identidade profissional a fim de que a universidade conheça seus discentes e construa pontes, proporcionando, consequentemente, que a relação experiencial seja considerada relevante na construção da formação humana e acadêmico-profissional dos/as universitários/ as. Portanto, trata-se de uma perspectiva subjetiva e política, que nos faz ver a necessidade da transformação social, tão desejada pela Pedagogia progressista libertadora, através da consciência crítica.
\end{abstract}

Palavras-chave: Prática pedagógica. Narrativas (auto)biográficas; Infância; Linha do Tempo-Memória.

\begin{abstract}
Has the notion of experience and autobiographies been considered in pedagogical practices at the university? The main objective of this research was to describe and analyze autobiographical narratives using the Memory Timeline as a pedagogical tool in higher education in the Pedagogy course at the State University of Vale do Acaraú. We address the experience of narratives in higher education, that is, the need for teachers to talk about their practices in the classroom and consider the students' narratives. The Timeline, a playful-subjective activity, can be characterized as a narrative device for autobiographical narrative reflection of students and as a pedagogical tool in higher education from a dialectical-dialogical perspective. This educational practice, which evokes the memory of childhood in a dialogical and intersubjective way, is different from positivist instrumental rationality. This enables us to reflect on the relevance of the subjective dimension when developing the curriculum as it allows the university to know students and build bridges for an experiential relationshipimportant for developing human and academic-professional training of college students.
\end{abstract}

Keywords: Pedagogical practice. Autobiographical narratives; Childhood; Memory Timeline.

\title{
REFERÊNCIAS
}

ARIÈS, Philippe. História social da criança e da família. 2. ed. Rio de Janeiro: Editora LTC, 1981.

BUJES, Maria Isabel Edelweiss, DORNELLES, Leni Viera. Alguns modos de significar a infância. In: DORNELLES, Leni; BUJES Maria Isabel. (Orgs.). Educação e infância na era da informação. Porto Alegre: Mediações, 2012. 
LARROSA. Jorge. Sobre a experiência e o saber de experiência. Revista Brasileira de Educação, n. 19, jan./abr. 2002.

BRUNER, J. S. Atos de significação. Porto Alegre: Artes Médicas, 1997.

DELORY-MOMBERGER, Christine. Biografia e educação: figuras do indivíduo-projeto. Natal: EDUFRN; São Pulo: Paulus, 2008.

FREIRE, Paulo. Pedagogia da Autonomia: Saberes necessários à prática educativa. 25. ed. São Paulo: Editora Paz e Terra, 1996.

GIMENO SACRISTÁN, J. Poderes instáveis em educação. Porto Alegre: Artmed Sul, 1999.

HYPÓLITO, Álvaro, M. Trabalho docente, classe social e relações de gênero. Campinas: Papirus, 1997.

HOOKS, Bell. Ensinando a transgredir: a educação como prática da liberdade. São Paulo: Editora WMF Martins Fontes, 2019.

JOSSO, M. C. As Histórias de Vida como territórios simbólicos nos quais se exploram e se descobrem formas e sentidos múltiplos de uma existencialidade evolutiva singular-plural. In: PASSEGGI, M. da C. (Org.). Tendências da pesquisa (auto) biográfica. Natal: EDUFRN; São Paulo: Editora Paulus, 2008.

JOSSO, Marie Christine. As figuras de ligação nos relatos de formação: ligações formadoras, deformadoras e transformadoras. Educação e pesquisa, v. 32, n. 2, p. 373-383, 2006.

JOSSO, M.-C. A transformação de si a partir da narração de histórias de vida. Educação, Porto Alegre/RS, n. 3, v. 63, p. 413-438, set./dez. 2007.

LARROSA, Jorge. A operação ensaio: sobre o ensaiar e o ensaiar-se no pensamento, na escrita e na vida. Educação e Realidade, Porto Alegre, v. 29, n. 1, jan./jun. 2004.

LEVENFUS, Rosane S. Psicodinâmica da escolha profissional. Porto Alegre: Artes Médicas, 199

LIMA, Euvira Souza. Quando a criança não aprende a ler e a escrever. Palestra organizada pela Secretaria Municipal de Educação de Campinas para professores alfabetizadores, realizada em 30 mar. 2004.

NÓVOA, Antonio. Os professores e as histórias da sua vida. In: NÓVOA, A. (Org.). Vidas de Professores. 2. ed. Porto Editora, Portugal, 2013. p. 11-17.

PASSEGGI, M. C.; SOUZA, E. C.; VICENTINI, P. P. Entre a vida e a formação: pesquisa (auto) biográfica, docência e profissionalização. Educ. rev., Belo Horizonte , v. 27, n. 1, p. 369-386, abr. 2011.

PIMENTA, Selma Garrido. Formação de professores: identidade e saberes da docência. In: PIMENTA, Selma Garrido. (Org). Saberes Pedagógicos e Atividade Docente. São Paulo: Cortez, 2000.

PIMENTA, Selma Garrido. Formação de professores - Saberes da docência e identidade do professor. Revista da Faculdade de Educação, São Paulo, v. 22, n. 2, p. 72- 89, 1996.

PINEAU, Gaston; LE GRAND, Jean-Louise. As histórias de vida. Natal: EDUFRN, 2012.

RICOEUR, Paul. A memória, a história, o esquecimento. Tradução: alain François [et al.]. Campinas, São Paulo: Editora da Unicamp, 2007.

RÊGO, Luciane Borges do; LIME, Maria Vitória Ribas de Oliveira. Didática. Recife: UPE, 2010. $44 \mathrm{p}$. 
RESENDE, Haroldo de. Notas sobre modernidade, pedagogia e infância a partir de Michel Foucault. ETD: Educação Temática Digital, v. 12, n. 1, p.242-255, 2010.

SABÓIA, Railane Bento Vieira; ASTIGARRAGA, Andrea Abreu. A prática educativa no estágio supervisionado: uma perspectiva interdisciplinar. In: ADAD, Shara Jane Holanda Costa; Joana Dárc de Sousa Lima; BRITO, Antonia Edna (Orgs.). Práticas educativas: múltiplas experiências em educação. Fortaleza: EDUECE, 2021.

SANTOS, Boaventura de Sousa. Um discurso sobre as ciências. São Paulo: Cortez, 2008.

SANTOS, Boaventura de Sousa; ALMEIDA FILHO, Naomar. A universidade do século XXI: para uma universidade nova. Coimbra: Almedina, 2008.

SOUZA, Elton da Silva; ASTIGARRAGA, Andrea Abreu; CAVALCANTE, Maria Mikaele da Silva. Fronteira do mundo da vida Anti-Procusto: narrativas (auto)biográficas das (os) universitárias (os) do curso de Pedagogia. Revista Cocar, v. 14, n. 30, p. 1-17, set./dez. 2020.

SARAT, Magda; CAMPOS, Miria Izabel. Memórias da Infância e da Educação: abordagens eliasianas sobre as mulheres. Revista Educação \& Realidade, Porto Alegre, v. 42, n. 4, p. 1257-1277, out./dez. 2017. http://dx.doi.org/10.1590/2175-623664283. Acesso em: 24 jul. 2021.

VASCONCELOS, Ana Paula Martins Farias; ASTIGARRAGA, Andrea Abreu. Prática Docente Transformadora no Ensino Remoto em Tempos de Covid-19. Revista Ensino em Perspectiva, jul. 2021.

Recebido em Junho de 2021

Aprovado em Agosto de 2021 